\title{
Effects of Protective Resin Coating on the Surface Roughness and Color Stability of Resin-Based Restorative Materials
}

\author{
Bora Bagis, ${ }^{1}$ Tamer Tüzüner, ${ }^{2}$ Sedanur Turgut, ${ }^{3}$ Fatih Mehmet Korkmaz, ${ }^{3}$ \\ Özgüll Baygın, ${ }^{1}$ and Yıldırım Hakan Bağıs ${ }^{4}$ \\ ${ }^{1}$ Department of Prosthodontics, Faculty of Dentistry, Izmir Katip Celebi University, Izmir, Turkey \\ ${ }^{2}$ Department of Pediatric Dentistry, Faculty of Dentistry, Karadeniz Technical University, Trabzon, Turkey \\ ${ }^{3}$ Department of Prosthodontics, Faculty of Dentistry, Karadeniz Technical University, Trabzon, Turkey \\ ${ }^{4}$ Department of Restorative Dentistry, Faculty of Dentistry, Ankara University, Ankara, Turkey \\ Correspondence should be addressed to Bora Bagis; bbagis@yahoo.com
}

Received 5 May 2014; Accepted 16 July 2014; Published 5 August 2014

Academic Editor: Cornelis H. Pameijer

Copyright (C) 2014 Bora Bagis et al. This is an open access article distributed under the Creative Commons Attribution License, which permits unrestricted use, distribution, and reproduction in any medium, provided the original work is properly cited.

\begin{abstract}
The aim of this study was to evaluate the effects of nanofilled protective resin coating $(\mathrm{RC})$ on the surface roughness (Ra) and color stability $(\Delta E)$ of resin-based restorative materials (RM) (compomer (C), nanofilled composite (NF), and microhybrid composite $(\mathrm{MH})$ ) after being submitted to the ultraviolet aging (UV) method. Thirty-six specimens were prepared $(n=6$ for each group). The $\mathrm{Ra}$ and $(\Delta E)$ values and SEM images were obtained before and after UV. Significant interactions were found among the RM-RC-UV procedures for $\mathrm{Ra}(P<0.001)$. After the specimens were submitted to $\mathrm{UV}$, the Ra values were significantly increased, regardless of the RC procedure (with RC; $P<0.01$ for all, without RC; $\mathrm{C}(P<0.01)$, NF $(P<0.001)$, and $\mathrm{MH}(P<0.001))$ for each RM. Significant interactions were found between the RM-RC $(P<0.001)$ procedures for the $\Delta E$ values. The $\Delta E$ values were increased in each group after applying the RC procedures $(P<0.001)$. Protective RC usage for RM could result in material-related differences in Ra and $\Delta E$ as with used UV method.
\end{abstract}

\section{Introduction}

Tooth-colored composite materials have been widely used for aesthetic purposes [1-5]. Compomers, defined as "polyacidmodified resin composites," were introduced in the dental literature in the early 1990s and have commonly been used for primary and permanent tooth restorations $[6,7]$. Composites and compomers must have smooth surfaces to inhibit plaque accumulation [7-11].

In clinical situations, the longevity of restorations is commonly related to acceptable finishing and polishing properties, which provide smooth surfaces [4, 12, 13]. Surface coating procedures have been reported as beneficial methods for decreasing the rougher properties of dental resin-based restorative materials (RM) $[8,14-17]$. Furthermore, in such cases, surface coatings have not been able to fill whole surface irregularities $[18,19]$.

Higher surface roughness $(\mathrm{Ra})$ values $(>0.2 \mu \mathrm{m})$ have been reported as a risk factor for extensive plaque accumulation on dental materials and as the main contributor to the multifactorial discoloration of resin restorations $[4,8,12$, $20,21]$, which is strongly correlated with the inorganic fillers in RM [20,22-24]. The surface degradation and color stability characteristics of RM, without $[12,20]$ or with $[8,25]$ surface coatings, can be affected by several factors, including filler type, size [26], or exposure to colorant $[2,4,8]$. Moreover, the surface resistance of RM, with decreased filler particle sizes $(<1 \mu \mathrm{m})$, is not able to advance using surface coating materials $[4,18]$. Additionally, the coherence properties of surface coatings, which can alter the penetration into the restoration surface, have been evaluated in the literature [2730]. The long-term durability of these coatings with RM after implementing various aging procedures has shown that coatings can debond over time, which has been noted to be important by many researchers $[8,12]$.

Ultraviolet aging (UV) is a method that simulates clinical conditions, allowing the color differences of materials over time to be determined. As materials are exposed to a range of conditions, including UV light, temperature changes, and 
TABLE 1: Composition of the materials.

\begin{tabular}{|c|c|c|c|c|c|}
\hline Material & Manufacturer & Composition & Filler size & Lot number & Shade \\
\hline Compomer & $\begin{array}{c}\text { Dyract eXtra } \\
\text { (Dentsply DeTrey, } \\
\text { Konstanz, Germany) }\end{array}$ & $\begin{array}{l}\text { Urethane dimethacrylate (UDMA), Carboxylic acid } \\
\text { modified dimethacrylate (TCB resin), triethyleneglycol } \\
\text { dimethacrylate (TEGDMA), trimethacrylate resin, } \\
\text { camphorquinone, ethyl-4-dimethylaminobenzoate, } \\
\text { butylated hydroxytoluene (BHT), UV stabiliser, } \\
\text { strontium-alumino-sodium-fluoro-phosphor-silicate } \\
\text { glass, highly dispersed silicon dioxide, strontium fluoride, } \\
\text { iron oxide, and titanium dioxide pigments }\end{array}$ & $0.8 \mu \mathrm{m}$ & 11004002055 & A3 \\
\hline $\begin{array}{l}\text { Nanofilled } \\
\text { composite }\end{array}$ & $\begin{array}{c}\text { Nanosit (Nordiska } \\
\text { Dental AB, } \\
\text { Ängelholm, Sweden) }\end{array}$ & $\begin{array}{l}\text { Silanated barium glass, bisphenol A } \\
\text { diglycidylmethacrylate (BisGMA), 1,6-hexanediol } \\
\text { dimethacrylate, fumed silica, ethyl } 4 \\
\text { dimethylaminobenzoate, camphorquinone, titanium } \\
\text { dioxide, Dye (iron oxides), 2,4-dihydroxybenzophenone, } \\
\text { and butylated hydroxyl toluene }\end{array}$ & $7 \mathrm{~nm}$ & 0510 & $\mathrm{~A} 3$ \\
\hline $\begin{array}{l}\text { Microhybrid } \\
\text { composite }\end{array}$ & $\begin{array}{c}\text { Gradia Direct X (GC } \\
\text { Co., Tokyo, Japan) }\end{array}$ & $\begin{array}{l}\text { Urethane dimethacrylate (UDMA), bisphenol A } \\
\text { diglycidylmethacrylate (BisGMA), } \\
\text { Fluoro-alumino-silicate glass, silica powder, } \\
\text { prepolymerized filler, dimethacrylate, and } \\
\text { camphorquinone }\end{array}$ & $0.85 \mu \mathrm{m}$ & 1104073 & $\mathrm{~A} 3$ \\
\hline $\begin{array}{l}\text { Nanofilled } \\
\text { coating }\end{array}$ & $\begin{array}{l}\text { G-Coat Plus (GC Co., } \\
\text { Tokyo, Japan) }\end{array}$ & $\begin{array}{l}\text { Methylmethacrylate, multifunctional methacrylate, and } \\
\text { camphorquinone }\end{array}$ & $\begin{array}{c}35-40 \mu \mathrm{m} \\
\text { nanofiller particles }\end{array}$ & 0908061 & \\
\hline
\end{tabular}

continuous humidity, artificially accelerated aging simulates clinical parameters as closely as possible [31]. This technique has been used to investigate the $\mathrm{Ra}$ and discoloration of dental materials [32-34]. Nevertheless, the durability of these surface coatings on RM and their possible long-term effects remain unknown.

The aim of this study was to evaluate the effects of nanofilled protective resin coating (RC) on the surface roughness $(\mathrm{Ra})$ and color stability $(\Delta E)$ of RM (compomer $(\mathrm{C})$, nanofilled composite (NF), and microhybrid composite $(\mathrm{MH})$ ) after being submitted to UV tests. The null hypothesis of this study was that the RC procedure would not change the surface roughness or color values of the RM after UV.

\section{Materials and Methods}

2.1. Specimen Preparation. Resin-based restorative materials, one compomer (C) and two composite resins (NF and $\mathrm{MH}$ ), with or without the resin coating (RC), were used in this study with the shade of A3 (Table 1). A total of 36 diskshaped specimens (10 $\mathrm{mm}$ in diameter and $2 \mathrm{~mm}$ in height) were prepared, covered with clear strips and light cured perpendicularly (Elipar FreeLight 2, $3 \mathrm{M}$ ESPE, St. Paul, MN, USA, for $20 \mathrm{~s}$ ) in plastic molds for both the Ra and $\Delta E$ tests ( $n=6$ for each group). After polymerization was completed, the specimens were divided into two groups, and half were treated with the RC by using microtip applicator with the same above light curing device for $20 \mathrm{~s}$. Then, the specimens were stored at $37^{\circ} \mathrm{C}$ and $100 \%$ relative humidity for 24 hours to ensure complete polymerization. One specimen, before and after the UV testing from each group, was stored for scanning electron microscopy (SEM) analysis. The tested groups are shown in Table 1.
2.2. Ultraviolet Aging (UV). The specimens were subjected to UV using an Atlas UV 2000 testing machine (Material Testing Technology LLC, Chicago, IL, USA). Aluminum plates were prepared in accordance with the sample sizes, and the specimens were inserted into the molds of the plates and subjected to aging tests. All of the specimens were exposed to ultraviolet light and water spray for 300 hours in the testing machine. The glazed surface of each specimen was continuously exposed to the light source. The back panel temperature ranged between $38^{\circ} \mathrm{C}$ (dark) and $70^{\circ} \mathrm{C}$ (light), and the relative humidity was $95 \%$ (dark) or $50 \%$ (light). The dry bulb temperature was $38^{\circ} \mathrm{C}$ in the dark stage and $47^{\circ} \mathrm{C}$ in the light stage. The testing cycle consisted of 40 minutes of light only, 20 minutes of light with a front water spray, 60 minutes of light only, and 60 minutes in the dark with a back water spray. The total exposure energy was $150 \mathrm{~kJ} / \mathrm{m}^{2}$.

2.3. Surface Roughness ( $R a)$. The average surface roughness of the specimens was measured with a surface profilometer (MarSurf PS1; Mahr, GmbH, Göttingen, Germany). To measure the roughness profile value, the diamond stylus $(5 \mu \mathrm{m}$ tip radius) was moved across the surface under a constant load of $3.9 \mathrm{mN}$. The instruments were calibrated by using a standard reference specimen and then set to travel at a speed of $0.100 \mathrm{~mm} / \mathrm{s}$ with a range of $600 \mu \mathrm{m}$ during testing. Surface roughness was measured 5 times for each specimen in the central part; the average value was obtained and defined as the $\mathrm{Ra}$.

2.4. Color Stability $(\Delta E)$ Evaluation. The color measurements were obtained with a colorimeter (ShadeEye NCC, Shofu, Japan) in a viewing booth, under D65 standard illumination on a white background, and these measurements were based 
TABLE 2: Three-way ANOVA table for interactions of Ra values.

\begin{tabular}{lcccrr}
\hline Interactions & Sum of squares & df & Mean square & $F$ & \multicolumn{1}{c}{ P } \\
RM-RC & 0.381 & 2 & 0.190 & 0.824 & 17.677 \\
RM-UV & 0.622 & 2 & 0.311 & 15.266 & $<0.001$ \\
RC-UV & 0.269 & 1 & 0.269 & 3.867 & $<0.001$ \\
RM-RC-UV & 0.136 & 2 & 0.068 & $=0.028$ \\
\hline
\end{tabular}

TABLE 3: Surface roughness $(\mathrm{Ra})$ values of the groups (mean $\pm \mathrm{SD})$.

\begin{tabular}{lccrr}
\hline \multirow{2}{*}{ Groups $(n=5)$} & \multicolumn{2}{c}{ Without RC } & \multicolumn{2}{c}{ With RC } \\
& Before UV & After UV & Before UV & $0.17 \pm 0.02^{\mathrm{A}, \mathrm{a}, \mathrm{l}}$ \\
C & $0.19 \pm 0.07^{\mathrm{A}, \mathrm{a}, \mathrm{l}}$ & $0.29 \pm 0.03^{\mathrm{A}, \mathrm{b}, 2}$ & $0.17 \pm 0.09^{\mathrm{A}, \mathrm{b}, 3}$ \\
NF & $0.19 \pm 0.06^{\mathrm{A}, \mathrm{a}, \mathrm{l}}$ & $0.30 \pm 0.05^{\mathrm{A}, \mathrm{b}, 2}$ & $0.18 \pm 0.03^{\mathrm{A}, \mathrm{a}, 1}$ & $0.46 \pm 0.03^{\mathrm{A}, \mathrm{b}, 3}$ \\
MH & $0.07 \pm 0.02^{\mathrm{B}, \mathrm{a}, 1}$ & $0.41 \pm 0.07^{\mathrm{B}, \mathrm{b}, 2}$ & $0.19 \pm 0.08^{\mathrm{A}, \mathrm{a}, \mathrm{l}}$ & $1.06 \pm 0.09^{\mathrm{B}, \mathrm{b}, 3}$ \\
\hline
\end{tabular}

In each column (among the RM), the same superscript capital letters indicate no significant differences with respect to their $\mathrm{UV}$ or RC procedures $(P>0.05)$. In each row (for the individual RM), the same lowercase superscript letters indicate no significant differences $(P>0.05)$, but different letters indicate significant differences before and after UV for the individual RC procedure $(P<0.05)$.

In each row (for individual conditions of the UV procedure; before or after), the same numbers indicate no significant differences $(P>0.05)$, but different numbers indicate significant differences without and with the RC procedure $(P<0.05)$.

on the ISO standards (ISO 7491). Before the experimental measurements, the colorimeter was calibrated according to the manufacturer's instructions, and it was positioned in the middle of each sample. The $L^{*} a^{*} b^{*}$ color notation of each specimen was measured consecutively three times, and the average of the three readings was calculated to yield the initial color of the specimen. The Commission Internationale de l'Eclairage (CIE) system was used to evaluate the $\Delta E$ (i.e., the degree of perceptible color change) based on three coordinates: $L^{*}, a^{*}$, and $b^{*} . L$ (lightness or brightness value) corresponds to the $L^{*}$ of the CIE Lab* system and represents the lightness/darkness of a color; $a^{*}$ is a measurement of redness (positive) or greenness (negative); and $b^{*}$ is a measurement of yellowness (positive) or blueness (negative). The CIE color difference is calculated with the following equation:

$\Delta E=\left[\left(\Delta L^{*}\right)^{2}+\left(\Delta a^{*}\right)^{2}+\left(\Delta b^{*}\right)^{2}\right]^{1 / 2}$.

2.5. Scanning Electron Microscopy (SEM). Samples were randomly selected from each group (before and after UV with RC) and gold-coated with an ion coating unit (Polaron SC 500 Sputter Coater; Quorum Technologies, Ashford, UK). Those samples were then evaluated and photographed under a SEM (EVO L10; Carl Zeiss, Oberkochen, Germany) to determine the surface alterations.

2.6. Statistical Analysis. Statistical evaluations were performed with statistical software (SPSS v15.0 for Windows; SPSS Inc., Chicago, IL, USA). Three-way ANOVA and Fisher's LSD test were used for analyzing the Ra values and two-way ANOVA and Fisher's LSD were used for comparing the $\Delta E$ values at a confidence interval of $95 \%$.

\section{Results}

3.1. Surface Roughness (Ra). Three-way ANOVA revealed significant interactions between the RM-RC $(P<0.001)$,
RM-UV $(P<0.001)$, RC-UV $(P<0.001)$, and RM-RC-UV $(P=0.028)$ for the Ra values (Table 2$)$.

The surface roughness $(\mathrm{Ra})$ values of the groups were shown in Table 3 . The MH samples exhibited significantly lower values in the without $\mathrm{RC} /$ before $\mathrm{UV}$ procedures than the $\mathrm{C}$ and NF samples $(P=0.003)$. In the without $\mathrm{RC} / \mathrm{after}$ UV procedures, the $\mathrm{MH}$ samples showed significantly higher values than the $\mathrm{NF}(P=0.003)$ and $\mathrm{C}(P=0.001)$ samples. In the with $\mathrm{RC} /$ before UV procedures, no significant differences were found among the groups $(P>0.05)$. In the with $\mathrm{RC} / \mathrm{after}$ UV procedures, the $\mathrm{MH}$ samples showed higher values than the NF $(P=0.007)$ and C $(P=0.003)$ samples.

The without RC procedures after UV conditions revealed that the Ra values were significantly higher in the $\mathrm{C}(P=$ $0.007)$, NF $(P<0.001)$ and MH groups $(P<0.001)$ compared to the before UV conditions. The with RC procedures revealed that $\mathrm{Ra}$ values were significantly higher for after UV conditions in the C $(P=0.005)$, NF $(P=0.006)$, and $\mathrm{MH}$ groups $(P=0.007)$ compared to the before UV conditions. In all of the groups, no significant differences were found between the with and without RC procedures under the before UV conditions $(P>0.05)$. However, significant differences were found between the with and without RC procedures in the after UV conditions for the $\mathrm{C}(P=0.028)$, NF $(P=0.001)$, and MH $(P<0.001)$ materials.

3.2. Color Stability $(\Delta E$ ). Two-way ANOVA for $\Delta E$ (which was calculated from $L^{*} a^{*} b^{*}$ difference between before UV and after UV procedures) revealed significant interactions among the RM-RC procedures $(P<0.001)$ (Table 4$)$.

$\Delta E$ values of the groups are shown in Table 5 . The $\mathrm{MH}$ samples had significantly lower values than the NF $(P<$ $0.001)$ and $\mathrm{C}(P<0.001)$ samples without the RC procedure. In the with RC procedures, significantly lower values were found in the $\mathrm{C}$ group than in the NF $(P=0.02)$ group, and the $\mathrm{MH}$ samples also showed significantly lower values than 
TABLE 4: Two-way ANOVA table for interactions of $\Delta E$ values.

\begin{tabular}{|c|c|c|c|c|c|}
\hline Interactions & Sum of squares & $\mathrm{df}$ & Mean square & $F$ & $P$ \\
\hline $\mathrm{RM}$ & 154.655 & 2 & 77.328 & 126.727 & $<0.001$ \\
\hline $\mathrm{RC}$ & 197.543 & 1 & 197.543 & 323.740 & $<0.001$ \\
\hline RM-RC & 28.541 & 2 & 14.271 & 23.387 & $<0.001$ \\
\hline
\end{tabular}

TABLE 5: $\Delta E$ values of the groups (mean $\pm \mathrm{SD}$ ).

\begin{tabular}{lcc}
\hline Groups $(n=5)$ & Without RC (after UV) & With RC (after UV) \\
& $\Delta E$ values & $\Delta E$ values \\
\hline $\mathrm{C}$ & $6.21 \pm 0.90^{\mathrm{A}, \mathrm{a}}$ & $9.28 \pm 0.47^{\mathrm{A}, \mathrm{b}}$ \\
$\mathrm{NF}$ & $5.73 \pm 1.34^{\mathrm{A}, \mathrm{a}}$ & $12.38 \pm 0.44^{\mathrm{B}, \mathrm{b}}$ \\
$\mathrm{MH}$ & $3.34 \pm 0.48^{\mathrm{B}, \mathrm{a}}$ & $5.68 \pm 0.64^{\mathrm{C}, \mathrm{b}}$ \\
\hline
\end{tabular}

In each column (among the RM), the same superscript capital letters indicate no significant differences $(P>0.05)$ with respect to their UV or RC procedures $(P>0.05)$.

In each row (for the individual restorative material), the same lowercase superscript letters indicate no significant differences $(P>0.05)$, but different letters indicate significant differences before and after UV for the individual RC procedure $(P<0.05)$.

the $\mathrm{C}(P<0.001)$ and NF $(P<0.001)$ samples. In all of the tested individual RM, the $\Delta E$ values were significantly higher in the with RC procedures, than in the without RC procedures $(P<0.001)$.

3.3. SEM Evaluations. According to the SEM findings, all of the tested materials showed almost smooth surfaces before UV procedure, irrespective of the material property of C (Figure 1(a)), NF (Figure 1(b)), and MH (Figure 1(c)). However, rougher surface irregularities were observed after the UV in C (Figure 2(a)) and NC (Figure 2(b)) of the groups with the RC procedure. The most prominent rough surface irregularities were obtained in the $\mathrm{MH}$ composite group with the RC procedure after UV (Figure 2(c)).

\section{Discussion}

The null hypothesis of this study was rejected. The coating procedure resulted in altered $\mathrm{Ra}$ and $\Delta E$ values in all of the tested groups after being submitted to the UV procedure.

The most common method for testing the effects of coating procedures on the surface texture of materials has been reported as using these sealants with previously applied conventional polishing procedures $[4,7,8,12,35,36]$. Thus, less rough surfaces could be obtained without the presence of defects, which resulted from the finishing and polishing procedures. However, such findings revealed that the thin layer of surface coating material might eliminate the surface irregularities or defects of inadequately polished composite restorations [8] and that this procedure also had little effect on previously polished surfaces [18]. In this study, to eliminate the potential beneficial effects of coating procedures on grinded polished surfaces, only a Mylar strip was used. Although this technique has not been commonly used in this type of study, it might be considered a "worst case scenario" for clinical conditions compared to the polished surfaces since the polishing quality depends upon the timeconsuming properties of the operators [13].

The manufacturer of the UV machine used in the present study has claimed that $300 \mathrm{~h}$ of accelerated weathering $\left(150 \mathrm{~kJ} / \mathrm{m}^{2}\right)$ is equivalent to 1 year of clinical service [31]; however, clinical validation of this claim is not available. Ultraviolet exposure with temperature and humidity changes might better simulate the oral environment $[12,36-38]$. In the present study, the specimens were aged for $150 \mathrm{~kJ} / \mathrm{m}^{2}$ because RM has been reported to undergo the most significant changes during this initial period [38]. Moreover, the Ra values, which were less than $0.2 \mu \mathrm{m}$ before the aging procedure, indicated clinically acceptable smooth surfaces for all of the groups, irrespective of the material property or RC procedure, even after the Mylar strip was used (Figures 1(a), 1(b), and $1(c)$ ). In previous reports, different aging procedures were used to measure the Ra values of the RM $[4,8,12]$. However, no clear evidence was found regarding the effects of the coating procedures on the RM, particularly after the materials were submitted to different aging procedures. After being submitted to the UV procedure, all of the tested materials had significantly higher and clinically unacceptable Ra values $(>0.2 \mu \mathrm{m})$ than their before UV measurements, irrespective of the RC procedure for all tested RM. This feature might be considered a material-dependent factor, which could be related to the aging method that is used in this study.

Before the UV procedure, the surface textures of RM with RC were found similar (Figures 1(a), 1(b), and 1(c)). After the UV, the SEM findings revealed prominent surface irregularities with more debonded and cracked surface features of the RC material in the $\mathrm{MH}$ group (Figure 2(c)) compared with the other groups (C and NF) (Figures 2(a) and 2(b)). The debonded feature of the coating procedure obtained in all of the tested materials exhibited material-dependent coherence properties. Because the same manufacturer as the RC material fabricated the MH composite, the surface areas could potentially be attached powerfully while detaching the cracked surface layers and subsequently exposing the rougher subsurface areas after the UV. Although the C group had a similar filler size to the $\mathrm{MH}$ material, significantly lower Ra values were obtained after UV. This finding could be related to the glass polyalkenoate composition being identical to that of the glass ionomers. Previous researchers have indicated that the coating procedure could properly seal the porosities and cracks in glass ionomers $[16,17]$. With the poorer surface finishing properties of $\mathrm{C}$ materials compared with composites [11], the application of a thin layer of coating material would increase the likelihood of fewer rougher surfaces being exhibited after UV. According to this finding, the possible benefits of using $\mathrm{C}$ materials to coat teeth, particularly primary teeth $[6,7]$, should not be 


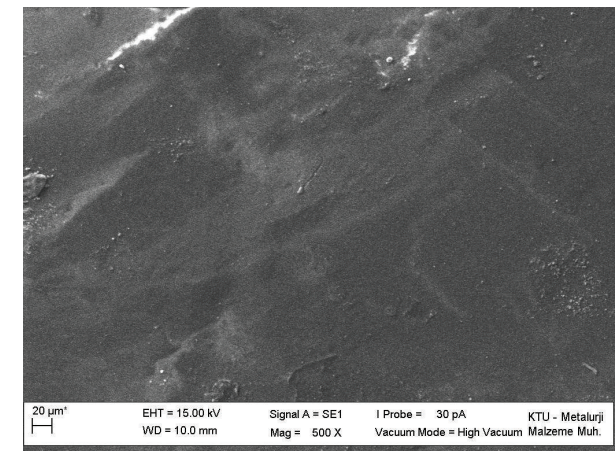

(a)

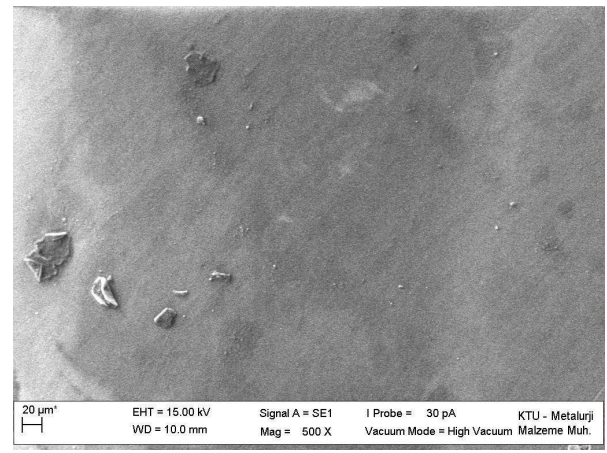

(b)

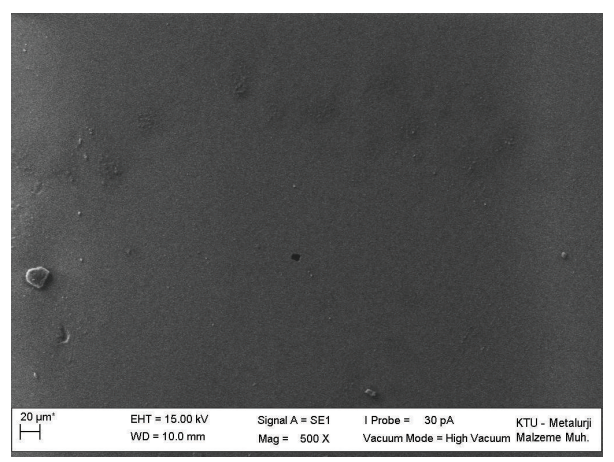

(c)

FIGURE 1: SEM evaluations of the samples with RC before UV. (a) Compomer, (b) nanofilled composite, and (c) microhybrid composite (Mag $\times 500$ ).

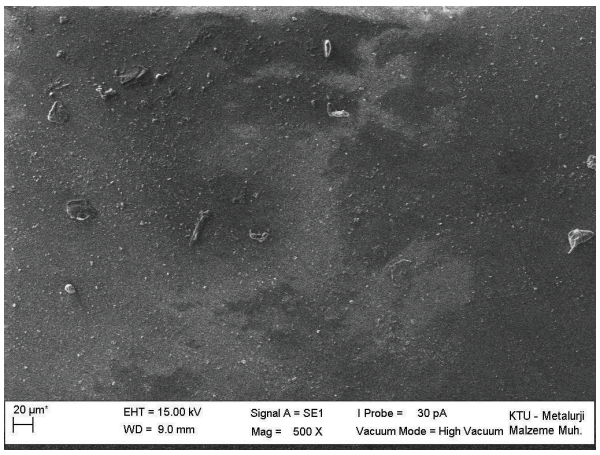

(a)

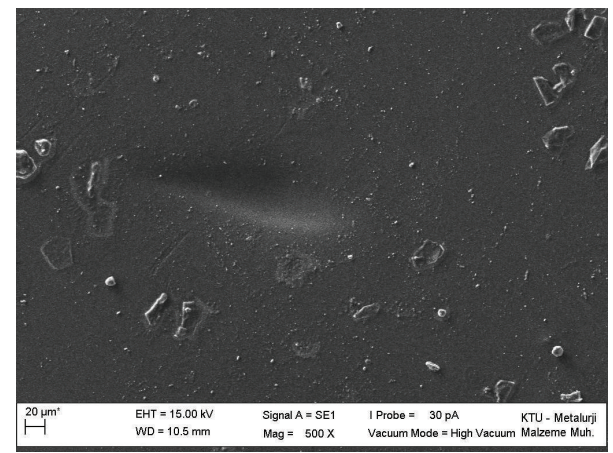

(b)

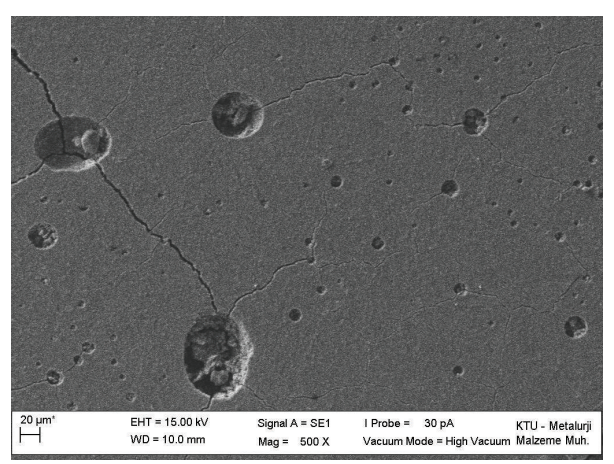

(c)

FIGURE 2: SEM evaluations of the samples with RC after UV. (a) Compomer, (b) nanofilled composite, and (c) microhybrid composite (Mag $\times 500)$. 
overlooked because of their provisional usage in the pediatric population.

Increased $\mathrm{Ra}$ is also known to be a major predisposing factor for the extrinsic discoloration of $\operatorname{RM}[8,20,22,24]$. To simulate the oral environmental conditions and to determine the $\Delta E$ of $\mathrm{RM}$, several in vitro methods, including storage in water, dark and dry situations, exposure to UV radiation, and exposure to staining solutions, have been used $[8,33]$. Color stability can be obtained visually and by colorimetry or spectrophotometry [20, 21]. Additionally, few studies have stated that coating procedures have negative effects on the $\Delta E$ of RM with different aging procedures [8]. Nevertheless, the effects of coating and the aging-related discoloration differences among coatings and dental materials remain unknown. For the above-mentioned reasons, the $\Delta E$ values of the tested materials (with or without RC) were evaluated after being submitted to the UV.

Clinically reasonable color change values were interpreted as being $<3.5[33,38]$. In the present study, all of the groups exhibited $\Delta E$ values greater than 3.5 after UV, except for the $\mathrm{MH}$ group (3.34 $\Delta E$ ), which was considered clinically unacceptable. Color changes in RM induced by UV irradiation have been correlated with chemical alterations in the initiator system, the activators, and the resin itself. The degradation of residual amines and oxidation of residual unreacted carbon-carbon double bonds culminate in the formation of yellowing compounds [36-38]. In addition, the physicochemical properties of the monomers used in a resin matrix can influence resistance to staining [37]. As these materials age, the water sorption characteristics of the resin monomers could contribute to differences in the degree of $\Delta E[33,38]$. In the present study, all of the materials showed significantly increased $\Delta E$ patterns with the RC procedure compared with their counterparts without RC. The RC procedures can result in prominent cracked and rougher surfaces after UV; the most prominent $\Delta E$ value was found in the NF group. This finding might have been due to the chemical alterations of these RM after UV.

These findings indicate that every restorative dental material requires its own treatment modality to obtain and maintain surfaces that are as smooth as possible. The protective RC of RM might be a risk factor for $\mathrm{Ra}$ and $\Delta E$.

\section{Conclusions}

Within the limitations of this study, the following conclusions can be drawn.

(1) Protective RC usage for RM might not be an advantage for the materials' $\mathrm{Ra}$ and $\Delta E$ in the long term.

(2) The Ra and discoloration values of RM increased after UV.

(3) Protective RC usage for RM might result in more discolored and rougher surfaces than without RC.

(4) Protective RC usage for RM could result in materialrelated differences in $\mathrm{Ra}$ and $\Delta E$ in the long term.

\section{Conflict of Interests}

The authors declare that there is no conflict of interests regarding the publication of this paper.

\section{References}

[1] A. U. Yap, K. W. Lye, and C. W. Sau, "Surface characteristics of tooth-colored restoratives polished utilizing different polishing systems," Operative Dentistry, vol. 22, no. 6, pp. 260-265, 1997.

[2] V. V. Badra, J. J. Faraoni, R. P. Ramos, and R. G. Palma-Dibb, "Influence of different beverages on the microhardness and surface roughness of resin composites," Operative Dentistry, vol. 30, no. 2, pp. 213-219, 2005.

[3] H. Lu, L. B. Roeder, L. Lei, and J. M. Powers, "Effect of surface roughness on stain resistance of dental resin composites," Journal of Esthetic and Restorative Dentistry, vol. 17, no. 2, pp. 102108, 2005.

[4] D. Sarac, Y. S. Sarac, S. Kulunk, C. Ural, and T. Kulunk, "The effect of polishing techniques on the surface roughness and color change of composite resins," Journal of Prosthetic Dentistry, vol. 96, no. 1, pp. 33-40, 2006.

[5] Y. Korkmaz, E. Ozel, N. Attar, and G. Aksoy, "The influence of one-step polishing systems on the surface roughness and microhardness of nanocomposites," Operative Dentistry, vol. 33, no. 1, pp. 44-50, 2008.

[6] A. Avşar and N. Tuloglu, "Effect of different topical fluoride applications on the surface roughness of a colored compomer," Journal of Applied Oral Science, vol. 18, no. 2, pp. 171-177, 2010.

[7] C. M. Bollen, P. Lambrechts, and M. Quirynen, "Comparison of surface roughness of oral hard materials to the threshold surface roughness for bacterial plaque retention: a review of the literature," Dental Materials, vol. 13, no. 4, pp. 258-269, 1997.

[8] B. Zimmerli, T. Koch, S. Flury, and A. Lussi, "The influence of toothbrushing and coffee staining on different composite surface coatings," Clinical Oral Investigations, vol. 16, no. 2, pp. 469479, 2012.

[9] M. Ikeda, K. Matin, T. Nikaido, R. M. Foxton, and J. Tagami, "Effect of surface characteristics on adherence of S. mutans biofilms to indirect resin composites," Dental Materials Journal, vol. 26, no. 6, pp. 915-923, 2007.

[10] S. B. de Fúcio, R. M. Puppin-Rontani, F. G. de Carvalho, R. O. De Mattos-Graner, L. Correr-Sobrinho, and F. Garcia-Godoy, "Analyses of biofilms accumulated on dental restorative materials," American Journal of Dentistry, vol. 22, no. 3, pp. 131-136, 2009.

[11] A. U. Yap, S. H. Yap, C. K. Teo, and J. J. Ng, "Finishing/polishing of composite and compomer restoratives: effectiveness of onestep systems," Operative Dentistry, vol. 29, no. 3, pp. 275-279, 2004.

[12] A. Catelan, A. L. F. Briso, R. H. Sundfeld, and P. H. Dos Santos, "Effect of artificial aging on the roughness and microhardness of sealed composites," Journal of Esthetic and Restorative Dentistry, vol. 22, no. 5, pp. 324-330, 2010.

[13] N. Attar, "The effect of finishing and polishing procedures on the surface roughness of composite resin materials," Journal of Contemporary Dental Practice, vol. 8, no. 1, pp. 027-035, 2007.

[14] R. Cilli, M. C. R. de Mattos, H. M. Honorio, D. Rios, P. A. de Araujo, and A. Prakki, "The role of surface sealants in the roughness of composites after a simulated toothbrushing test," Journal of Dentistry, vol. 37, no. 12, pp. 970-977, 2009. 
[15] C. R. Perez, R. Hirata Jr., A. H. M. F. T. Silva, E. M. Sampaio, and M. S. Miranda, "Effect of a glaze/composite sealant on the 3D surface roughness of esthetic restorative materials," Operative Dentistry, vol. 34, no. 6, pp. 674-680, 2009.

[16] U. Lohbauer, N. Krämer, G. Siedschlag et al., "Strength and wear resistance of a dental glass-ionomer cement with a novel nanofilled resin coating," American Journal of Dentistry, vol. 24, no. 2, pp. 124-128, 2011.

[17] V. T. K. Diem, M. J. Tyas, H. C. Ngo, L. H. Phuong, and N. D. Khanh, "The effect of a nano-filled resin coating on the 3-year clinical performance of a conventional high-viscosity glassionomer cement," Clinical Oral Investigations, vol. 18, no. 3, pp. 753-759, 2014.

[18] L. B. Roeder, W. H. Tate, and J. M. Powers, "Effect of finishing and polishing procedures on the surface roughness of packable composites," Operative Dentistry, vol. 25, no. 6, pp. 534-543, 2000.

[19] G. L. Dickinson and K. F. Leinfelder, "Assessing the long-term effect of a surface penetrating sealant," The Journal of the American Dental Association, vol. 124, no. 7, pp. 68-72, 1993.

[20] M. S. Festuccia, F. Garcia Lda, D. R. Cruvinel, and C. Pires-DeSouza Fde, "Color stability, surface roughness and microhardness of composites submitted to mouthrinsing action," Journal of Applied Oral Science, vol. 20, no. 2, pp. 200-205, 2012.

[21] D. Dietschi, G. Campanile, J. Holz, and J. M. Meyer, "Comparison of the color stability of ten new-generation composites: an in vitro study," Dental Materials, vol. 10, no. 6, pp. 353-362, 1994.

[22] A. H. L. Tjan and C. A. Chan, "The polishability of posterior composites," The Journal of Prosthetic Dentistry, vol. 61, no. 2, pp. 138-146, 1989.

[23] Y. K. Lee, "Influence of filler on the difference between the transmitted and reflected colors of experimental resin composites," Dental Materials, vol. 24, no. 9, pp. 1243-1247, 2008.

[24] E. U. Çelik, A. Aladağ, L. Ş. Türkün, and G. Yilmaz, "Color changes of dental resin composites before and after polymerization and storage in water," Journal of Esthetic and Restorative Dentistry, vol. 23, pp. 179-188, 2011.

[25] D. R. Cruvinel, F. Garcia Lda, S. Consani, and F. de Carvalho Panzeri Pires-de-Souza, "Composites associated with pulpprotection material: color-stability analysis after accelerated artificial agin," European Journal of Dentistry, vol. 4, pp. 6-11, 2010.

[26] W. Buchalla, T. Attin, R. D. Hilgers, and E. Hellwig, "The effect of water storage and light exposure on the color and translucency of a hybrid and a microfilled composite," Journal of Prosthetic Dentistry, vol. 87, no. 3, pp. 264-270, 2002.

[27] K. Kawai and K. F. Leinfelder, "Effect of resin composite adhesion on marginal degradation," Dental Materials Journal, vol. 14, no. 2, pp. 211-220, 1995.

[28] C. Y. G. Takeuchi, V. H. Orbegoso Flores, R. G. Palma Dibb, H. Panzeri, E. H. G. Lara, and W. Dinelli, "Assessing the surface roughness of a posterior resin composite: effect of surface sealing," Operative Dentistry, vol. 28, no. 3, pp. 281-286, 2003.

[29] B. M. Owens and W. W. Johnson, "Effect of new generation surface sealants on the marginal permeability of class $\mathrm{V}$ resin composite restorations," Operative Dentistry, vol. 31, no. 4, pp. 481-488, 2006.

[30] J. S. Reid, W. P. Saunders, and Y. Y. Chen, "The effect of bonding agent and fissure sealant on microleakage of composite resin restorations," Quintessence International, vol. 22, no. 4, pp. 295298, 1991.
[31] G. Heydecke, F. Zhang, and M. E. Razzoog, "In vitro color stability of double-layer veneers after accelerated aging," Journal of Prosthetic Dentistry, vol. 85, no. 6, pp. 551-557, 2001.

[32] E. Kilinc, S. A. Antonson, P. C. Hardigan, and A. Kesercioglu, "Resin cement color stability and its influence on the final shade of all-ceramics," Journal of Dentistry, vol. 39, no. 1, pp. e30-e36, 2011.

[33] A. Sarafianou, S. Iosifidou, T. Papadopoulos, and G. Eliades, "Color stability and degree of cure of direct composite restoratives after accelerated aging," Operative Dentistry, vol. 32, no. 4, pp. 406-411, 2007.

[34] M. K. Takahashi, S. Vieira, R. N. Rached, J. B. de Almeida, M. Aguiar, and E. M. de Souza, "Fluorescence intensity of resin composites and dental tissues before and after accelerated aging: a comparative study," Operative Dentistry, vol. 33, no. 2, pp. 189195, 2008.

[35] P. H. dos Santos, S. Pavan, S. Consani, L. C. Sobrinho, M. A. C. Sinhoreti, and J. N. A. Filho, "In vitro evaluation of surface roughness of 4 resin composites after the toothbrushing process and methods to recover superficial smoothness.," Quintessence international, vol. 38, no. 5, pp. e247-e253, 2007.

[36] K. A. Schulze, S. J. Marshall, S. A. Gansky, and G. W. Marshall, "Color stability and hardness in dental composites after accelerated aging," Dental Materials, vol. 19, no. 7, pp. 612-619, 2003.

[37] R. D. Douglas, "Color stability of new-generation indirect resins for prosthodontic application," Journal of Prosthetic Dentistry, vol. 83, no. 2, pp. 166-170, 2000.

[38] H. Lu and J. M. Powers, "Color stability of resin cements after accelerated aging," American Journal of Dentistry, vol. 17, no. 5, pp. 354-358, 2004. 


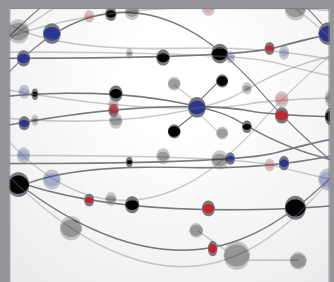

The Scientific World Journal
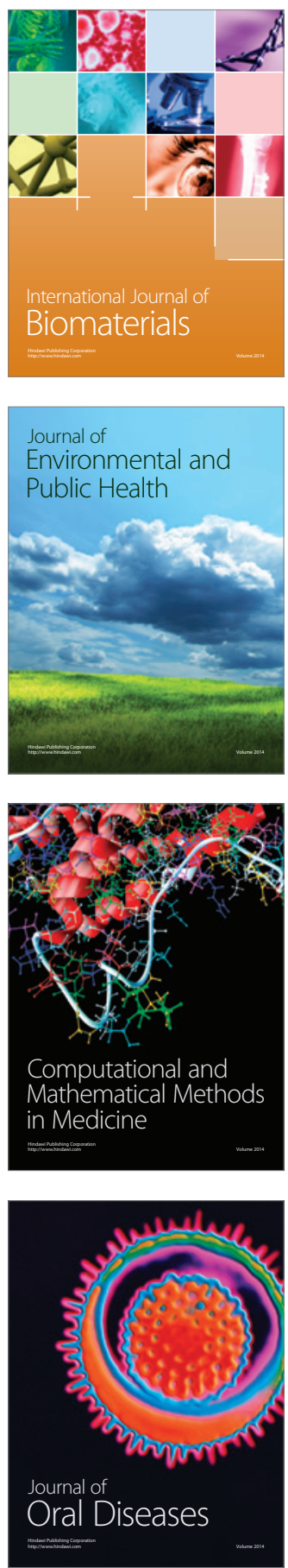
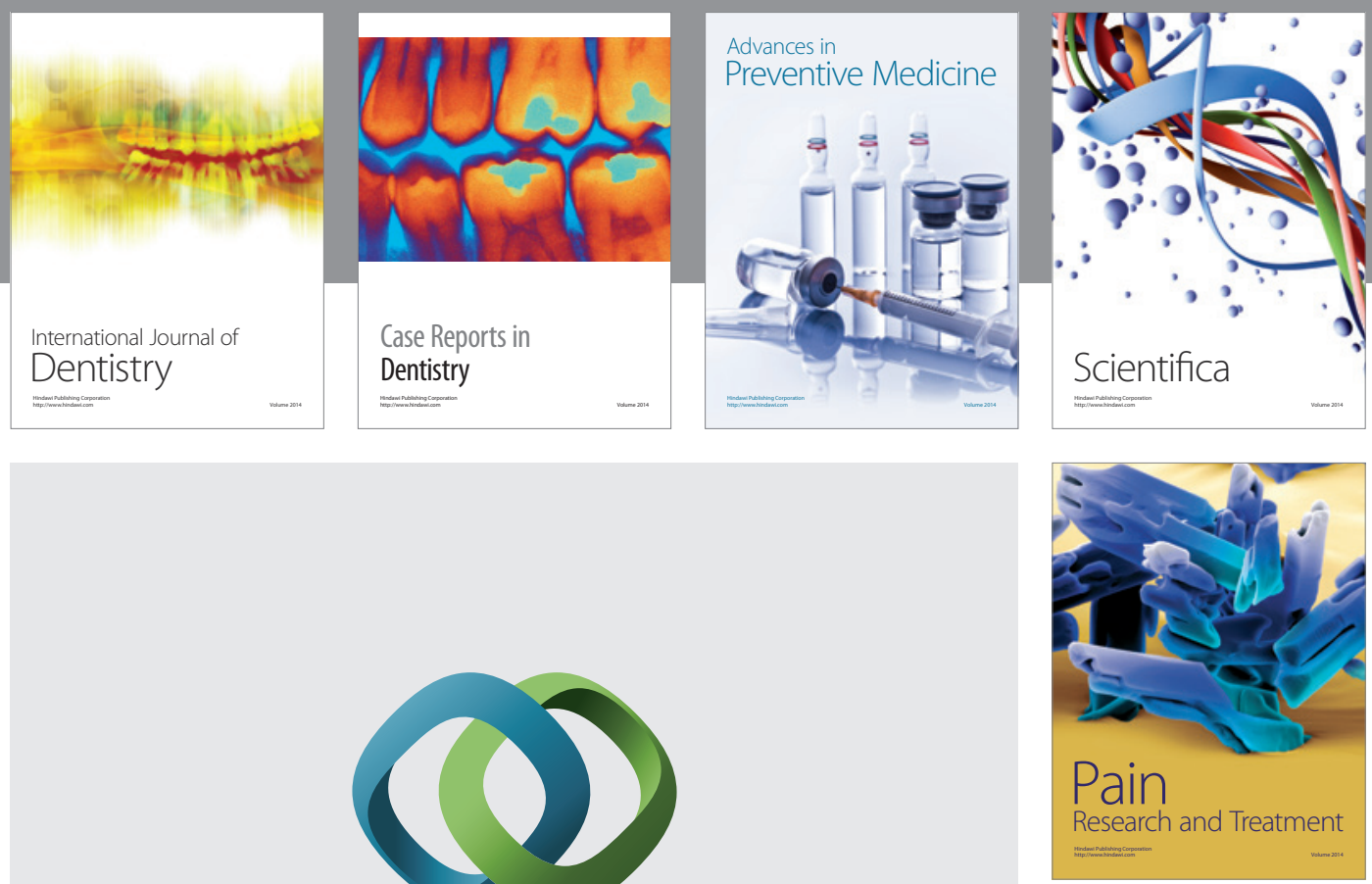

\section{Hindawi}

Submit your manuscripts at

http://www.hindawi.com
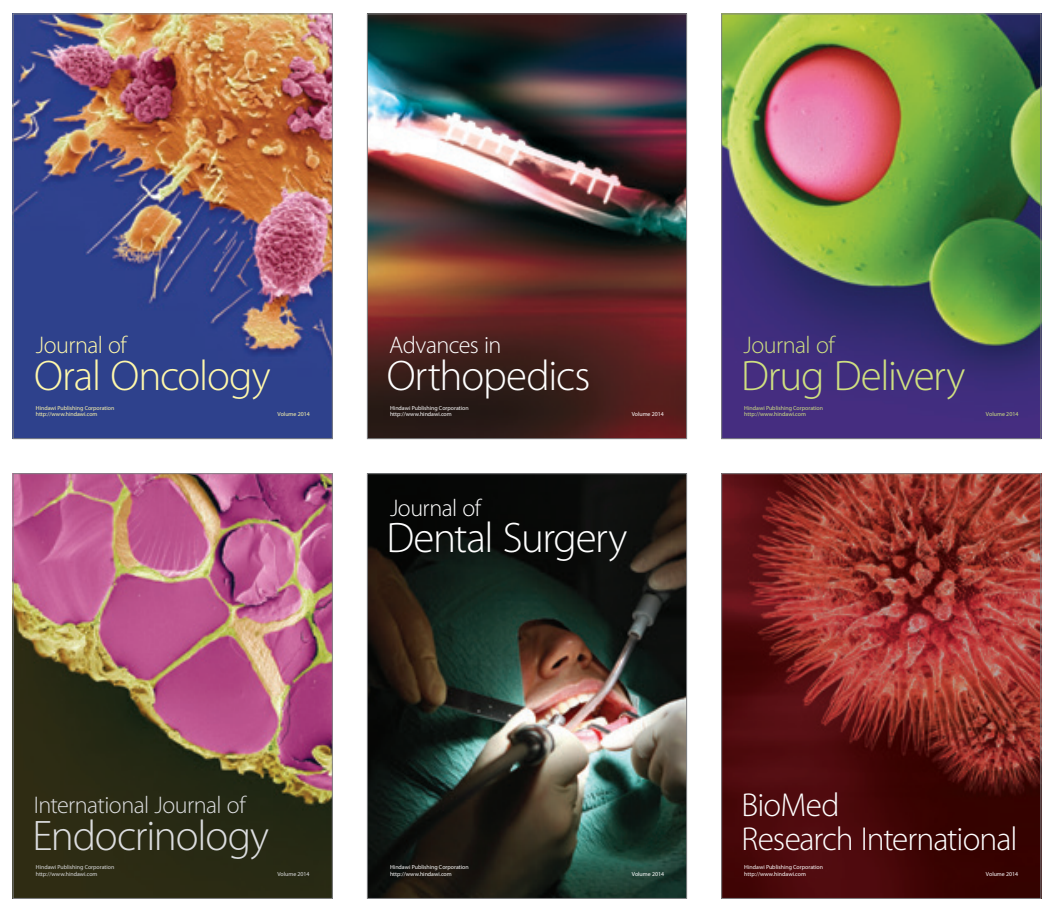

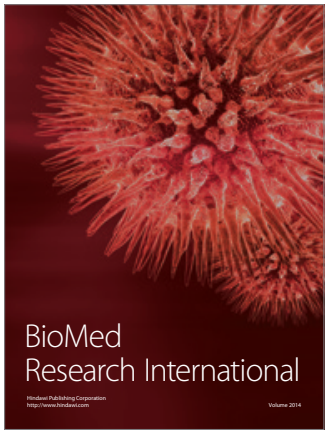

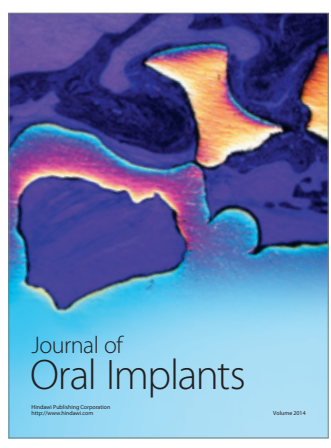
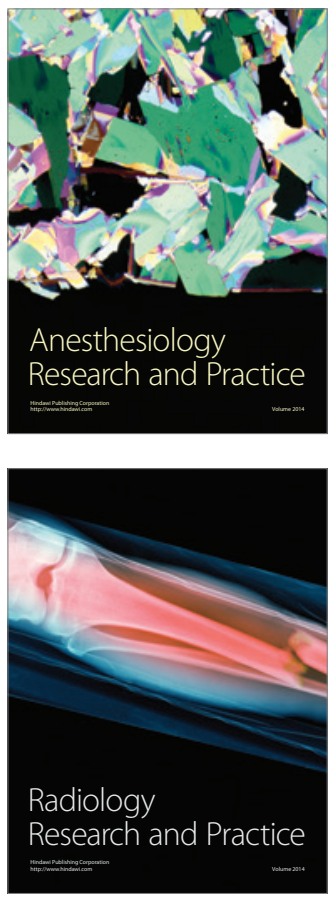